\title{
PEMETAAN KELAYAKAN LAHAN BUDI DAYA IKAN LAUT DI KECATAMAN MORO, KEPULAUAN RIAU: DENGAN PENDEKATAN SISTEM INFORMASI GEOGRAFIS
}

\author{
( Nyoman Radiarta*), Adang Saputra*), Ofri Johan*), dan Tri Heru Prihadi*)
}

\begin{abstract}
ABSTRAK
Sistem informasi geografis telah digunakan untuk menganalisis kelayakan lahan budi daya ikan laut di perairan Kecamatan Moro, Kepulauan Riau. Pengumpulan data lapangan telah dilakukan pada bulan Agustus dan Oktober 2004 dengan menggunakan metode acak sederhana. Parameter penting penentuan kelayakan lahan budi daya ikan laut sesuai dengan data yang dikumpulkan digolongkan atas dua kriteria yaitu faktor lingkungan (meliputi: kedalaman, kecerahan, kecepatan arus, dan tinggi gelombang) dan faktor kualitas perairan (meliputi: suhu, salinitas, kandungan oksigen, dan pH). Pembobotan faktor dan parameter kelayakan lahan dilakukan dengan menggunakan teknik multi kriteria analisis. Hasil analisis spasial dengan menggabungkan faktor lingkungan dan kualitas air, secara umum menunjukkan bahwa perairan Kecamatan Moro tergolong layak, cukup layak, atau sangat layak, dan tidak ditemukan daerah yang tidak layak untuk budi daya ikan laut.
\end{abstract}

ABSTRACT: Mapping of site suitability for marine fish aquaculture in adjacent water of Moro Sub District, Riau Archipelago: Geographic information systems approach. By: I Nyoman Radiarta, Adang Saputra, Ofri Johan, and Tri Heru Prihadi

This study used geographic information system to analysis site suitability of marine fish culture in adjacent water of Moro Sub District, Riau Archipelago. Simple random sampling was used for collecting data on August and October 2004. Important parameters for marine fish culture from field measurement were categorized into two criteria, namely environmental factor (include: bathymetry, transparency, water current, and wave height) and water quality factor (include: temperature, salinity, dissolve oxygen, and $\mathrm{pH}$ ). Multi criteria analysis (MCA) technique was used to weight of factors and parameters. Based on overlay of environmental factors and water quality factors using spatial analysis showed that most of areas of Moro sub district (Riau Archipelago) were identified as being suitable, moderately suitable or highly suitable, and none was identified as totally unsuitable for marine fish culture.

KEYWORDS: marine fish, aquaculture, GIS, Multi Criteria Analysis, Riau

\section{PENDAHULUAN}

Moro adalah salah satu Kecamatan dari Kabupaten Tanjung Balai Karimun yang daerahnya terdiri atas kepulauan dengan jumlah pulau mencapai 151 buah. Secara geografis Kecamatan ini terletak pada $103^{\circ} 33^{\prime}-$ $103^{\circ} 59^{\prime}$ Bujur Timur dan 0²8'30"-0 $0^{\circ} 30^{\prime \prime}$
Lintang Utara dengan luas wilayah mencapai $2.568 \mathrm{~km}^{2}$. Luas laut di Kecamatan Moro lebih besar dari luas daratan dengan luas masingmasing mencapai $1.915 \mathrm{~km}^{2}$ dan $653 \mathrm{~km}^{2}$.

Kegiatan perikanan tangkap merupakan mata pencaharian utama masyarakat Kecamatan Moro. Pada tahun 2000 perikanan tangkap

*) Peneliti pada Pusat Riset Perikanan Budidaya, Jakarta 
memberikan konstribusi sebesar 355 ton. Namun demikian, dengan karakteristik geografi kecamatan yang terdiri atas banyaknya pulaupulau kecil menjadikan kecamatan ini berpotensi bagi pengembangan budi daya laut. Besarnya potensi yang dimiliki ini, telah mendapat perhatian dan dukungan di tingkat kabupaten. Hal ini terbukti dengan ditetapkannya Kecamatan Moro sebagai sentra kegiatan budi daya laut yang dituangkan dalam tata ruang wilayah di tingkat kabupaten.

Perkembangan usaha budi daya laut, dewasa ini telah memberikan konstribusi nyata di antaranya: penyediaan bahan makanan (sea food), penyerapan tenaga kerja, peningkatan pendapatan, dan menurunnya tekanan terhadap sumber daya ikan akibat intensitas penangkapan yang tinggi. Namun di sisi lain perkembangan ini telah menimbulkan konflik dan penurunan mutu lingkungan. Konflik kepentingan dalam hal pemanfaatan lahan pesisir seringkali tidak dapat dihindari antar pengguna, di antaranya perikanan (budi daya dan penangkapan), navigasi, pariwisata, dan konservasi. Oleh sebab itu, untuk memastikan keberlanjutan kegiatan perikanan (budi daya laut), maka pengalokasian usaha di tempat yang sesuai sangatlah diperlukan untuk meminimalkan kompetisi dalam pemanfaatan pesisir, menghindari penurunan kondisi lingkungan, dan memastikan keberlanjutan usaha budi daya laut tersebut (GESAMP, 2001).

Sistem informasi geografis (SIG) merupakan sistem yang dirancang untuk menganalisis data spasial yang berhubungan dengan posisi geografis di bumi (Burrough \& McDonnell, 1998). Dibandingkan dengan metode tradisional, SIG mempunyai beberapa keuntungan di antaranya dapat menampilkan karakteristik lingkungan dan juga dapat melakukan analisis spasial sehingga dapat menyederhanakan permasalahan dan pemanfaatan waktu yang lebih efektif.

Pemanfaatan SIG dalam bidang perikanan budi daya sampai dewasa ini sudah cukup banyak semenjak pertama kali dipublikasikan tahun 1980- an (Kapetsky et al., 1987). Kajian kelayakan lahan berdasarkan spesies (ikan dan kekerangan) atau ekosistem (laut, pesisir, dan darat) merupakan satu contoh studi yang memanfaatkan teknologi SIG. Selain mengkaji kelayakan lahan secara tersendiri (Arnold et al., 2000; Pérez et al., 2005), SIG juga telah digunakan untuk kajian integrasi antar kegiatan di wilayah pesisir. Contoh kajian tersebut di antaranya yang dilaporkan oleh Pérez et al. (2003) yang menganalisis integrasi antara budi daya ikan laut dalam KJA dengan kegiatan pariwisata di Tenerife (Canary Islands). Sedangkan Goullerquer \& Le Moine (2002) mengkaji budi daya kekerangan yang sejalan dengan manajemen pesisir di Marennes- Oleron Bay dan Charentais, Prancis.

Penelitian ini bertujuan untuk melakukan analisis kelayakan lahan budi daya ikan laut, terutama bagi kegiatan budi daya ikan dalam keramba jaring apung (KJA) dengan menggunakan pendekatan SIG. Hasil dari penelitian ini diharapkan menjadi masukan bagi pemerintah daerah untuk membantu dalam pengambilan kebijakan penyusunan rencana tata ruang wilayah/ pesisir.

\section{BAHAN DAN METODE}

Penelitian in telah dilakukan di perairan Kecamatan Moro, Kabupaten Tanjung Balai Karimun, Provinsi Kepulauan Riau. Lokasi penelitian terbentang pada posisi $103^{\circ} 30^{\prime}$ - $104^{\circ} 00^{\prime}$ Bujur Timur dan $0^{\circ} 32^{\prime}-0^{\circ} 55^{\prime}$ Lintang Utara dengan luasan perairan sekitar $1.523 \mathrm{~km}^{2}$ (Gambar 1).

Pengumpulan data lapangan dilakukan pada Bulan Agustus dan Oktober 2004. Pengumpulan data pada bulan yang berbeda ini diharapkan dapat mewakili dua musim yaitu musim kemarau dan musim hujan. Metode yang dipakai dalam penelitian ini adalah metode survai yang dirancang berdasarkan SIG. Simple random sampling (Clark \& Hosking, 1986) merupakan teknik yang digunakan untuk penentuan titik pengamatan. Inisiasi survai dan data sekunder lainnya digunakan sebagai dasar untuk menentukan lokasi titik pengamatan. Sebanyak 87 titik pengamatan telah berhasil dikumpulkan (Gambar 1). Pengambilan data lapangan dilakukan pada kisaran waktu 9.00-15.00 MB. Data yang dikumpulkan dalam penelitian ini terdiri atas kedalaman, kecerahan, kecepatan arus, tinggi gelombang, suhu air, salinitas, kandungan oksigen (DO), dan pH. Diagram alur analisis kelayakan lahan budi daya ikan disajikan pada Gambar 2.

\section{Penentuan Skor dan Pembobotan}

Pengelompokan parameter yang berpengaruh terhadap kegiatan budi daya ikan laut didasarkan atas dua kategori yaitu faktor lingkungan (parameter yang berpengaruh terhadap daya tahan hidup ikan), meliputi 


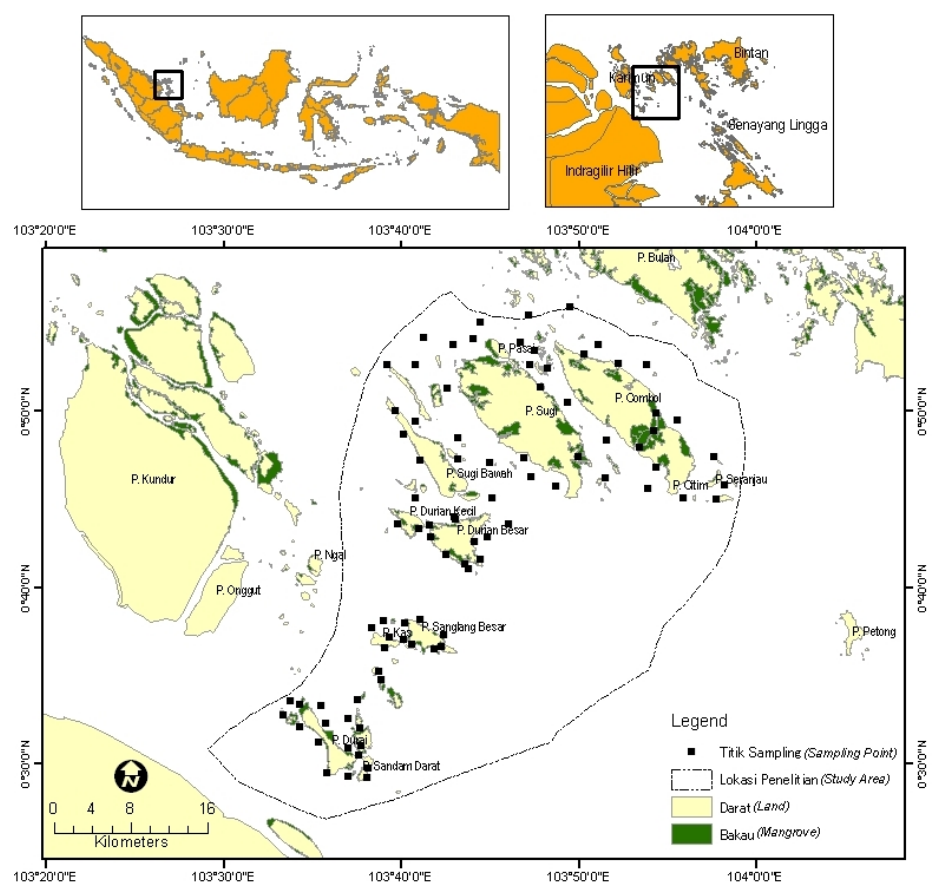

Gambar 1. Tampilan umum lokasi penelitian di perairan Kecamatan Moro dan distribusi lokasi pengamatan kualitas perairan

Figure 1. General features of study area at adjacent water of Moro Sub District and distribution of sampling points

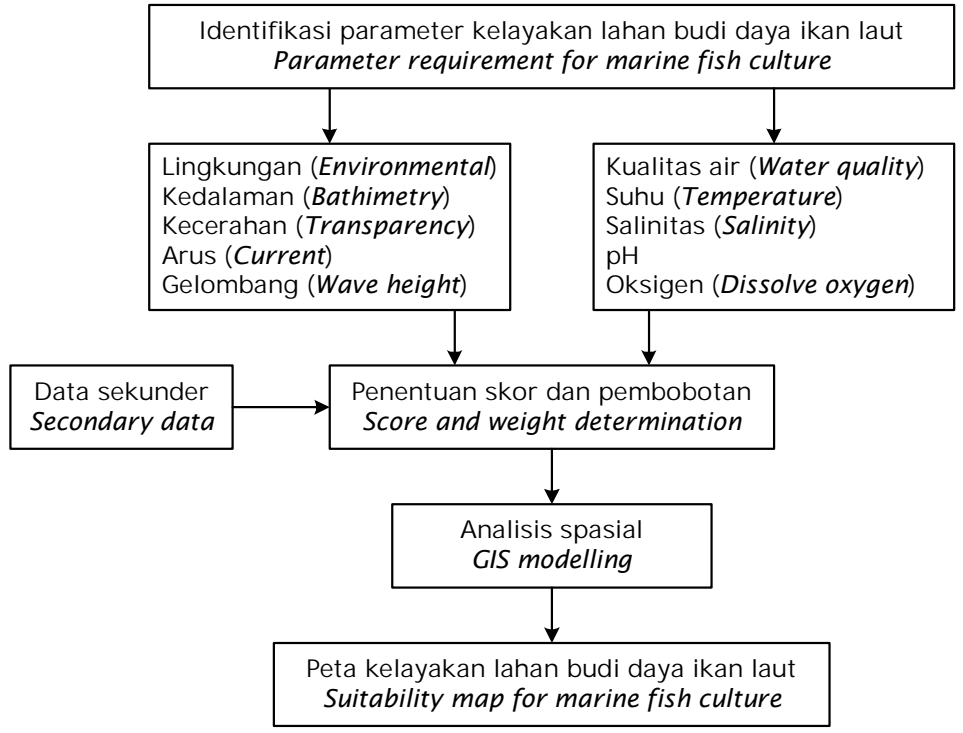

Gambar 2. Diagram alur penentuan kelayakan lahan budi daya ikan laut

Figure 2. Schematic diagram for determining suitability site of marine fish culture 
kedalaman, kecerahan, kecepatan arus, dan tinggi gelombang serta faktor kualitas perairan (parameter yang berpengaruh terhadap pertumbuhan dan daya tahan hidup ikan) yang meliputi: suhu air, salinitas, pH, dan DO.

Tingkat kesesuaian (skor) untuk menganalisis kelayakan lahan terdiri atas berbagai macam sistem skor, sebagai contoh skor 1-3 (Karthik et al., 2005); skor 1-5 (Buitrago et al., 2005); dan skor 1-8 (Pérez et al., 2003). Penelitian ini menggunakan skor 1 -4 (tidak layak-sangat layak) (Giap et al., 2005; Salam et al., 2003). Penentuan skor masing- masing parameter berdasarkan efek dari parameter tersebut bagi budi daya ikan laut. Rincian dari masing- masing skor adalah sebagai berikut:

1. Tidak layak: lokasi dapat dimanfaatkan bagi kegiatan budi daya ikan laut, namun membutuhkan biaya, tenaga, dan waktu yang sangat besar.
2. Cukup layak: lokasi dapat dimanfaatkan bagi kegiatan budi daya ikan laut, namun membutuhkan tenaga, biaya, dan waktu yang cukup besar.

3. Layak: lokasi dapat dimanfaatkan bagi kegiatan budi daya ikan laut dengan sedikit membutuh biaya dan waktu.

4. Sangat layak: ideal bagi kegiatan budi daya ikan laut

Kajian kelayakan lahan budi daya ikan pada penelitian ini lebih difokuskan untuk budi daya ikan dalam keramba jaring apung (KJA). Kriteria yang digunakan untuk penyusunan matrik kesesuaian mengacu pada Beveridge (1996). Tabel 1 menyajikan matrik kesesuaian untuk penentuan kelayakan lahan budi daya ikan laut dalam KJA

Sistem pembobotan yang digunakan dalam penelitian ini adalah Analytical hierarchy process (AHP) (Saaty, 1977; Malczewski, 1999). AHP

Tabel 1. Kesesuaian parameter lingkungan dan kualitas perairan untuk budi daya ikan laut dalam KJA

Table 1. Environmental and water quality requirements for marine fish cage culture

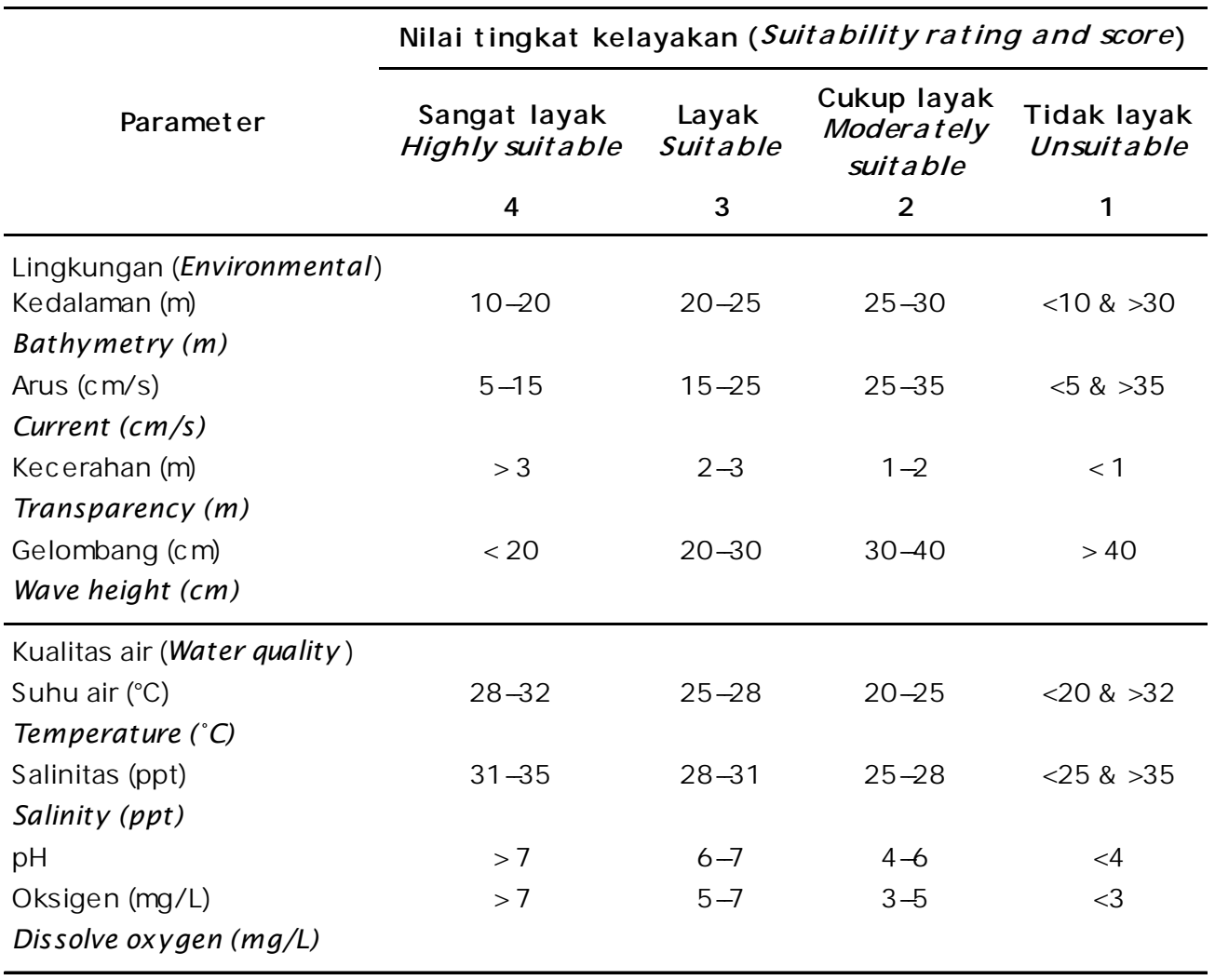


dilakukan dengan teknik yang dikenal dengan nama pair wise comparison dalam konteks pengambilan keputusan yang merupakan teknik dalam analisis multi kriteria. Masingmasing parameter diberikan bobot berdasarkan hasil survai dan studi literatur (expert opinions). Parameter yang mempunyai pengaruh dominan dan relatif tidak dapat diubah memiliki faktor pembobot yang paling besar, sebaliknya parameter yang kurang dominan memiliki faktor pembobot yang lebih kecil. Keunggulan dari teknik ini adalah bobot yang dibuat dapat diuji dengan melihat rasio konsistensi (consistency ratio, $\mathrm{CR}$ ). Rasio konsistensi baru dapat diterima jika $C R<0,1$, jika nilai tersebut lebih besar maka harus dilakukan pembobotan ulang. Nilai pembobotan yang digunakan dalam penelitian ini disajikan pada Tabel 2.

\section{Analisis Spasial}

Peta tematik untuk masing- masing parameter kelayakan Iahan budi daya ikan terlebih dahulu disusun sebelum dilakukan analisis spasial. Inverse Distance Weighted (IDW) interpolasi (Johnson et al., 2001) telah digunakan pada penelitian ini untuk mengkonversi data titik menjadi area (polygon). Hasil interpolasi tersebut kemudian dikelompokkan berdasarkan masing-masing faktor yaitu lingkungan dan kualitas perairan. Luasan perairan yang layak bagi kegiatan budi daya

Tabel 2. Matrik penentuan bobot parameter untuk analisis pemilihan lokasi budi daya ikan laut

Table2. Pair wise comparison matrix for assessing the relative important of criteria for site selection of marine fish culture

Lingkungan ( Environmental )

\begin{tabular}{lccccc}
\hline & $\begin{array}{c}\text { Kecerahan } \\
\text { Tranparency }\end{array}$ & $\begin{array}{c}\text { Kedalaman } \\
\text { Bathymetry }\end{array}$ & $\begin{array}{c}\text { Arus } \\
\text { Current }\end{array}$ & $\begin{array}{c}\text { Gelombang } \\
\text { Wave high }\end{array}$ & $\begin{array}{c}\text { Bobot } \\
\text { Weight }\end{array}$ \\
\hline Kecerahan (Tranparency) & 1 & 2 & 4 & 7 & 0.53 \\
Kedalaman (Bathymetry) & 12 & 1 & 2 & 3 & 0.26 \\
Arus (Current) & 14 & 12 & 1 & 2 & 0.14 \\
Gelombang (Wave high ) & 17 & 13 & 12 & 1 & 0.07 \\
\hline
\end{tabular}

Rasio konsistensi (Consistency ratio/CR ):0.0029

Kualitas air ( Water quality )

\begin{tabular}{lccccc}
\hline & $\begin{array}{c}\text { Suhu } \\
\text { Temperature }\end{array}$ & $\begin{array}{c}\text { Salinitas } \\
\text { Salinity }\end{array}$ & pH & $\begin{array}{c}\text { Oksigen } \\
\text { Dissolve } \\
\text { oxygen }\end{array}$ & $\begin{array}{c}\text { Bobot } \\
\text { Weight }\end{array}$ \\
\hline Suhu(Temperature) & 1 & 2 & 7 & 4 & 0.52 \\
Salinitas (Salinity) & 12 & 1 & 4 & 2 & 0.27 \\
$\mathrm{pH}$ & 17 & 14 & 1 & 12 & 0.07 \\
Oksigen (Dissolve oxygen ) & 14 & 12 & 2 & 1 & 0.14 \\
\hline
\end{tabular}

Rasio konsistensi (Consistency ratio/CR ): 0.0008

Kriteria kelayakan lahan (Criteria for site selection )

\begin{tabular}{lccc}
\hline & $\begin{array}{c}\text { Lingkungan } \\
\text { Environmental }\end{array}$ & $\begin{array}{c}\text { Kualitas air } \\
\text { Water quality }\end{array}$ & $\begin{array}{c}\text { Bobot } \\
\text { Weight }\end{array}$ \\
\hline Lingkungan(Environmental ) & 1 & $3 / 2$ & 0.6 \\
Kualitas air (Water quality ) & $2 / 3$ & 1 & 0.4 \\
\hline
\end{tabular}

Rasio konsistensi (Consistency ratio/CR ):0.000 
Tabel 3. Nilai kesesuaian untuk pemilihan lokasi budi daya ikan laut

Table 3. Overall suitability rating score for marine fish culture site selection

\begin{tabular}{lc}
\hline $\begin{array}{c}\text { Tingkat kelayakan } \\
\text { Suitability rating }\end{array}$ & $\begin{array}{c}\text { Kisaran nilai } \\
\text { ange of score }\end{array}$ \\
\hline Sangat layak (Highly suitable) & $0.8-1.0$ \\
Layak (Suitable) & $0.6--0.8$ \\
Cukup layak (Moderately suitable) & $0.4-0.6$ \\
Tidak layak (Unsuitable) & $0.0-0.4$ \\
\hline
\end{tabular}

ikan laut dihasilkan setelah seluruh parameter ditumpangsusunkan (overlay) berdasarkan skor dan bobot dengan menggunakan persamaan di bawah ini:

$$
A_{i}=\frac{\left(W_{1} r_{1}+W_{2} r_{2}+\ldots+W_{j} r_{i j}\right)}{n}
$$

di mana: $A_{i}$ adalah suitability index, $r_{i j}$ adalah tingkat kesesuaian (score) dari masing- masing parameter, $w_{\mathrm{j}}$ adalah nilai pembobot di mana $\mathrm{Sw}_{\mathrm{j}}=1$, dan $\mathrm{n}$ adalah jumlah sistem skor.

Tingkat kelayakan lahan secara utuh diperoleh dari hasil perhitungan di atas, kemudian dikelompokkan berdasarkan kisaran nilai dari masing-masing tingkat kalayakan seperti yang disajikan pada Tabel 3 .

\section{HASIL DAN BAHASAN}

Secara umum, kondisi iklim di lokasi penelitian sangat berpengaruh terhadap kondisi perairan. Terdapat empat musim yang terbagi berdasarkan arah mata angin (Anonim, 2000; Bappeda Riau, 2001) yaitu musim utara (Desember-Februari), timur (Maret-Juni), selatan (Juli-Agustus), dan barat (SeptemberNovember). Pada selang musim tertentu beberapa lokasi perairan di Kecamatan Moro memiliki tingkat kekeruhan perairan yang tinggi yang ditandai dengan rendahnya kecerahan perairan. Meskipun demikian, terdapat lokasilokasi yang sangat berpotensi bagi pengembangan budi daya laut karena adanya lokasi yang terlindung yang terdiri atas pulau- pulau kecil, selat, dan teluk serta berdekatan dengan lokasi pasar (lokal dan internasional) yaitu Batam, Singapura, dan Hongkong.

Secara umum kondisi lingkungan dan kualitas perairan di lokasi penelitian masih dalam batas toleransi kegiatan budi daya ikan laut.
Tabel 4 menyajikan kisaran nilai parameter lingkungan dan kualitas perairan di lokasi penelitian

Dari seluruh data lapangan yang dikumpulkan terlihat jelas bahwa tingkat kekeruhan yang cukup tinggi yang ditandai dengan kecerahan perairan yang rendah (Tabel 4) ditemukan hampir di seluruh perairan, terutama di sekitar perairan Pulau Durian Kecil dan Besar, Pulau Sangiang Besar, dan Pulau Durai. Tingkat kekeruhan yang tinggi di beberapa perairan mungkin disebabkan oleh adanya kegiatan penambangan pasir darat/laut yang masih banyak ditemukan di lokasi penelitian.

\section{Faktor Lingkungan}

Parameter lingkungan yang terdiri atas kecerahan perairan, kedalaman, kecepatan arus, dan tinggi gelombang merupakan parameter yang berpengaruh terhadap daya tahan hidup ikan laut (Nath et al., 2000). Kondisi tingkat kecerahan perairan di lokasi penelitian tergolong limit bagi keberlangsungan usaha budi daya ikan laut. Oleh karena itu parameter ini menjadi sangat penting dalam pembobotannya. Peta tematik hasil penggabungan dari masing- masing parameter lingkungan yang meliputi kecerahan, kedalaman, kecepatan arus, dan tinggi gelombang disajikan pada Gambar 3. Tabel 5 menyajikan luasan dan persentase tingkat kesesuaian lahan untuk budi daya ikan laut berdasarkan masing- masing faktor dan parameter.

Tingkat kelayakan lahan dari faktor lingkungan didominasi oleh kategori cukup layak sebesar $611 \mathrm{~km}^{2}$. Kategori sangat layak ditemukan di sekitar perairan Pulau Sugie dan Pulau Combol dengan luasan sebesar $211 \mathrm{~km}^{2}$. Perairan di kedua pulau tersebut umumnya memiliki tingkat kecerahan yang sangat baik. 
Tabel 4. Kisaran nilai parameter lingkungan dan kualitas air di lokasi penelitian Table 4. Value range of environmental factor and water quality at study area

\begin{tabular}{lcc}
\hline \multicolumn{1}{c}{ Parameter (Parameters) } & Satuan (Unit) & Kisaran nilai (Value range)* \\
\hline Lingkungan (Environmental) & & \\
Kecerahan (Transparency) & $\mathrm{m}$ & $0.25-6.0(1.5 \pm 1.2)$ \\
Kedalaman (Bathymetry) & $\mathrm{m}$ & $0.5-68(13.4 \pm 8.7)$ \\
Kecepatan arus (Water current) & $\mathrm{cm} / \mathrm{s}$ & $8--60(28.7 \pm 19.6)$ \\
Tinggi gelombang (Wave height) & $\mathrm{cm}$ & $5-80(20.0 \pm 21.2)$ \\
\hline Kualitas air (Water quality) & & \\
Suhu air (Temperature) & ${ }^{\circ} \mathrm{C}$ & $28.7-32.8(30.6 \pm 0.7)$ \\
Salinitas (Salinity) & $\mathrm{ppt}$ & $19-29(23.9 \pm 1.5)$ \\
pH & & $8.34-8.8(8.5 \pm 0.09)$ \\
Oksigen (Dissolve oxygen) & $\mathrm{mg} / \mathrm{L}$ & $4.37-10.01(7.2 \pm 1.1)$ \\
\hline
\end{tabular}

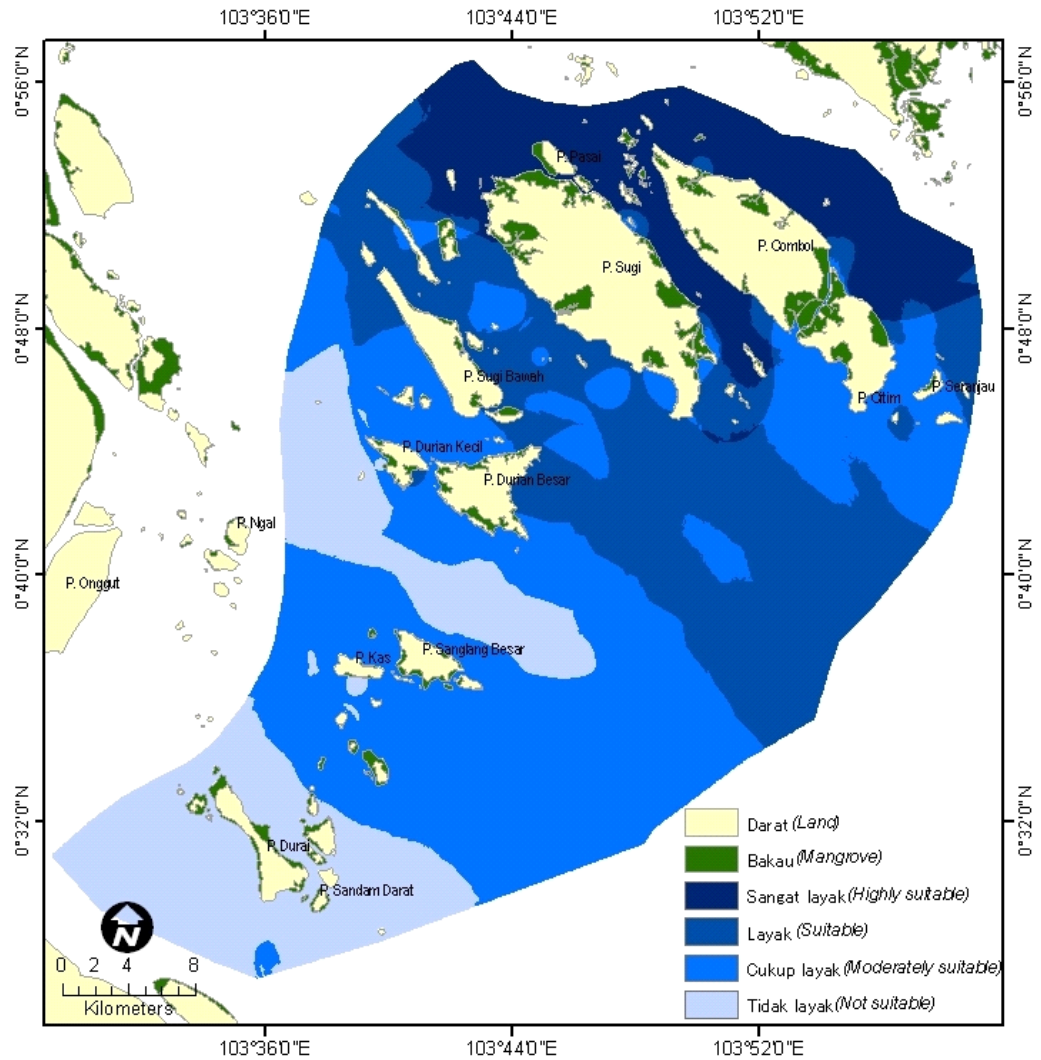

Gambar 3. Tingkat kelayakan lahan parameter lingkungan di lokasi penelitian

Figure 3. Map of suitability level for environmental parameter at study area

Demikian pula dengan parameter lingkungan lainnya seperti kedalaman, kecepatan arus, dan tinggi gelombang tergolong layak dan sangat layak. 


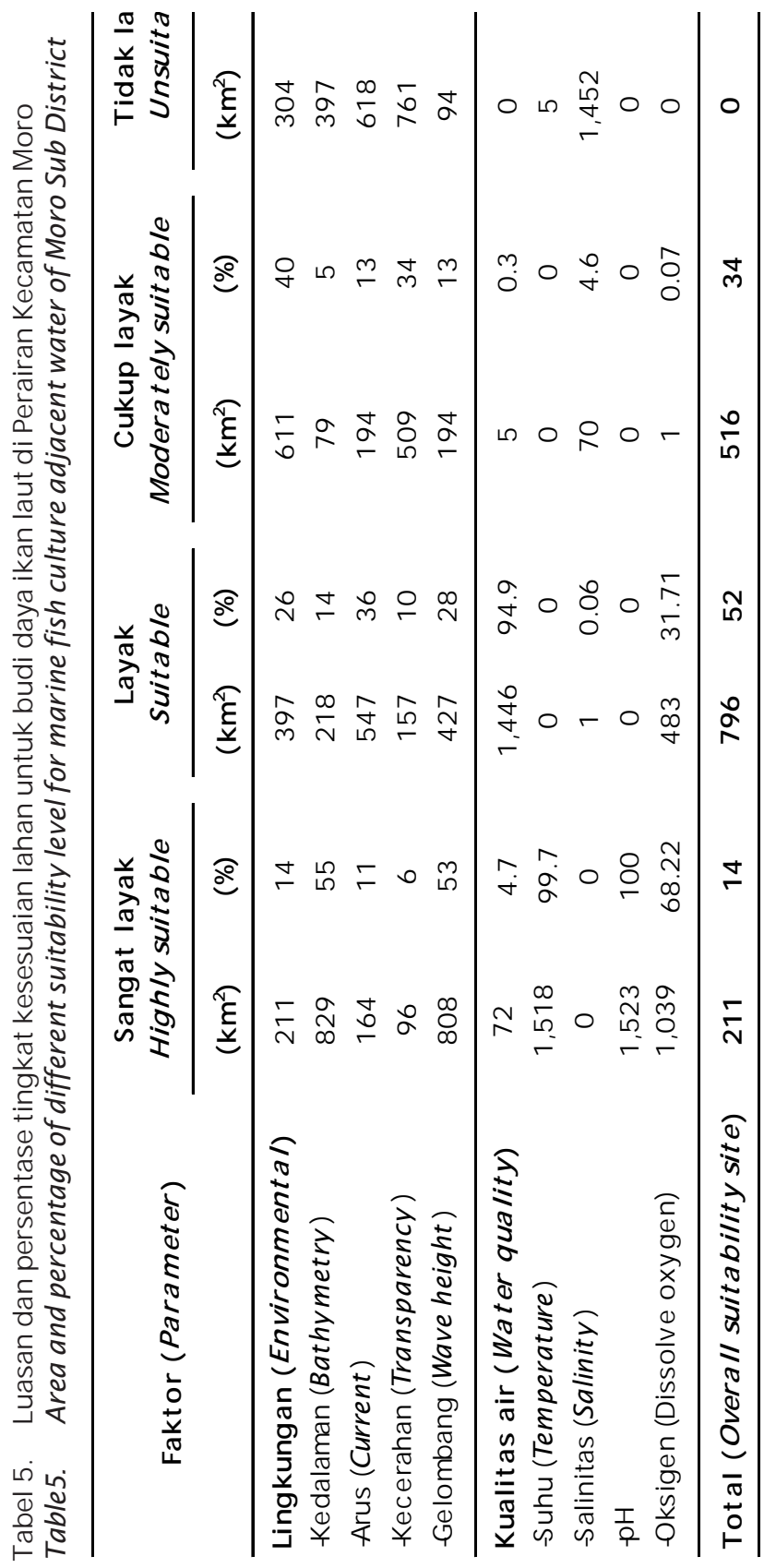


Kondisi tidak layak dari faktor lingkungan terletak di perairan sekitar Pulau Durai dan pulau- pulau kecil di sekelilingnya. Hal utama yang menyebabkan rendahnya tingkat kelayakan lahan di lokasi tersebut karena memiliki tingkat kekeruhan yang sangat tinggi (atau kecerahan yang sangat rendah). Nilai tingkat kecerahan di sekitar perairan ini dari hasil pengukuran di lapangan menunjukkan kisaran nilai tidak lebih dari $1 \mathrm{~m}$.

\section{Faktor Kualitas Perairan}

Parameter kualitas perairan yang terdiri atas suhu air, salinitas, kandungan oksigen, dan $\mathrm{pH}$ merupakan parameter berpengaruh terhadap pertumbuhan dan daya tahan hidup ikan laut (Nath et al., 2000). Peta tematik hasil penggabungan dari masing- masing faktor kualitas perairan yang meliputi suhu, salinitas, $\mathrm{pH}$, dan kandungan oksigen disajikan pada Gambar 4.
Secara umum kondisi kualitas perairan sangat mendukung bagi kegiatan budi daya ikan laut. Hasil penggabungan seluruh faktor kualitas perairan, menunjukkan bahwa hampir seluruh perairan $(94,9 \%)$ tergolong layak bagi kegiatan budi daya ikan. Kategori sangat layak hanya sekitar 4,7\% Kondisi yang sangat layak tersebar di bagian timur laut Pulau Combol dan sebagian kecil bagian barat Pulau Sugi. Tidak ditemukan lokasi yang tidak layak bagi kegiatan budi daya ikan laut dari faktor kualitas perairan.

Kelayakan lahan dilihat dari masing- masing parameter umumnya tergolong dalam kategori sangat layak (Tabel 5). Hanya salinitas perairan yang mempunyai nilai yang cukup rendah (19$29 \mathrm{ppt}$ ) sedangkan salinitas yang ideal untuk budi daya laut menurut Pulukadang (1995) berkisar antara 20-31 ppt, sehingga dari parameter ini hampir seluruh perairan tergolong tidak layak bagi kegiatan budi daya ikan laut.

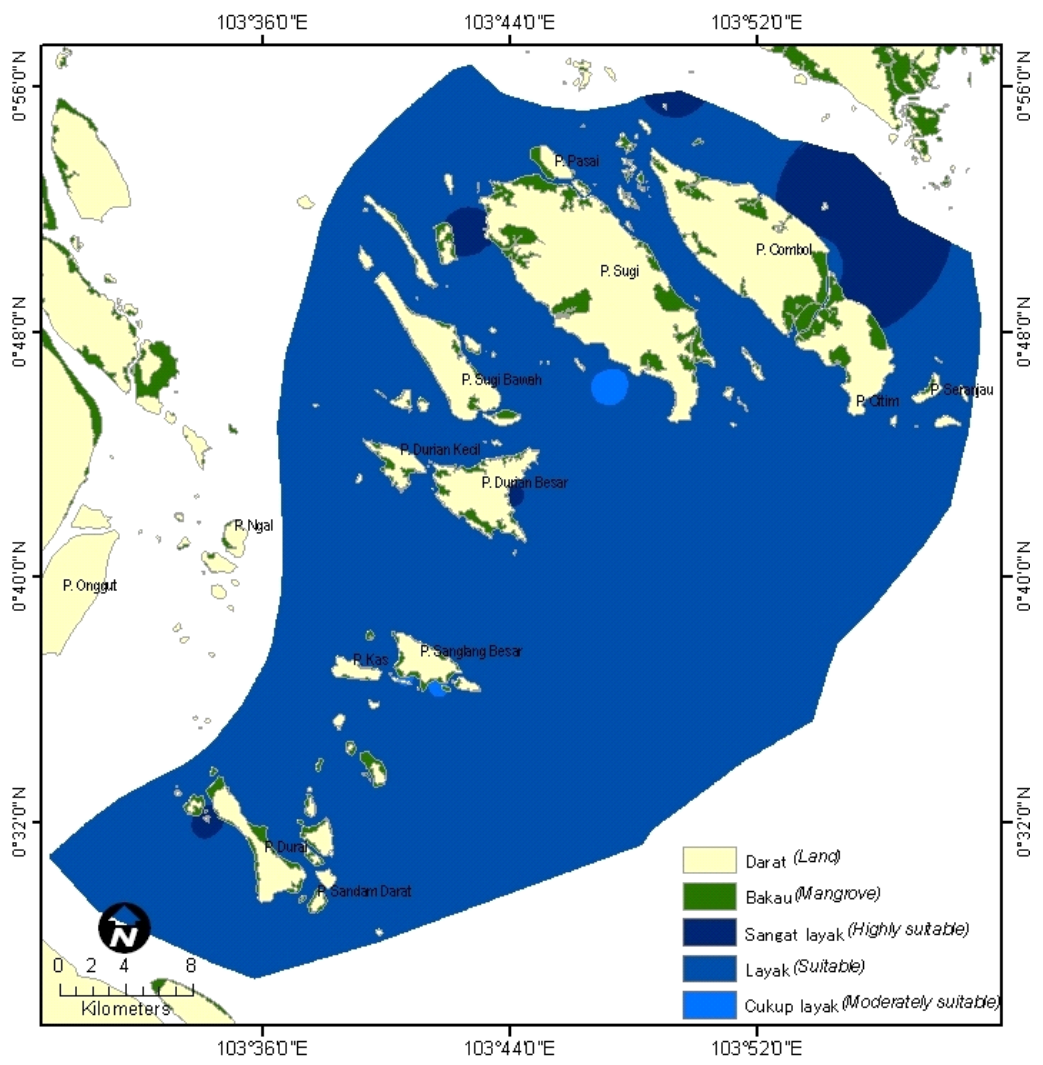

Gambar 4. Tingkat kelayakan lahan parameter kualitas perairan di lokasi penelitian

Figure 4. Map of suitability level for water quality parameter at study area 


\section{Kelayakan Lahan Budi Daya Ikan Laut}

Kelayakan Iahan budi daya ikan laut dihasilkan dengan menggabungkan semua peta tematik dari faktor lingkungan dan kualitas perairan. Dari total luasan daerah penelitian yang mencapai $1.523 \mathrm{~km}^{2}$, memiliki tingkat kelayakan lahan sebagai berikut: sangat layak sebesar $211 \mathrm{~km}^{2}$ (14\%), layak: $796 \mathrm{~km}^{2}(52 \%)$, dan cukup layak: $516 \mathrm{~km}^{2}$ (34\%) (Tabel 5). Peta tematik kelayakan lahan budi daya laut dapat dilihat pada Gambar 5.

Dari analisis spasial yang dilakukan menunjukkan bahwa kondisi kelayakan lahan yang dihasilkan sesuai dengan kondisi di lapangan. Hal ini terbukti dengan telah berlangsungnya kegiatan budi daya ikan laut dengan KJA oleh PT Indomarine Culture Industry yang berlokasi di daerah dengan kategori sangat layak (perairan sekitar Pulau Lemas, Desa Keban) (Gambar 5).

\section{KESIMPULAN}

Perairan Kecamatan Moro, potensial bagi pengembangan perikanan budi daya laut. Lokasi ini sangat strategis, karena berdekatan dengan pasar baik lokal maupun ekspor yaitu: Batam, Singapura, dan Hongkong.

Dari hasil kajian yang telah dilakukan terhadap kualitas perairan di Kecamatan Moro terdapat lokasi- lokasi yang sangat mendukung kegiatan budi daya ikan laut. Dari hasil penggabungan faktor lingkungan dan faktor kualitas perairan menunjukkan bahwa perairan di sekitar Pulau Combol dan Pulau Sugi dengan luasan mencapai $211 \mathrm{~km}^{2}$ merupakan lokasi yang sangat layak untuk kegiatan budi daya ikan laut menggunakan sistem keramba jaring apung.

Dengan karakteristik perairan yang memiliki tingkat kekeruhan yang cukup tinggi, harus

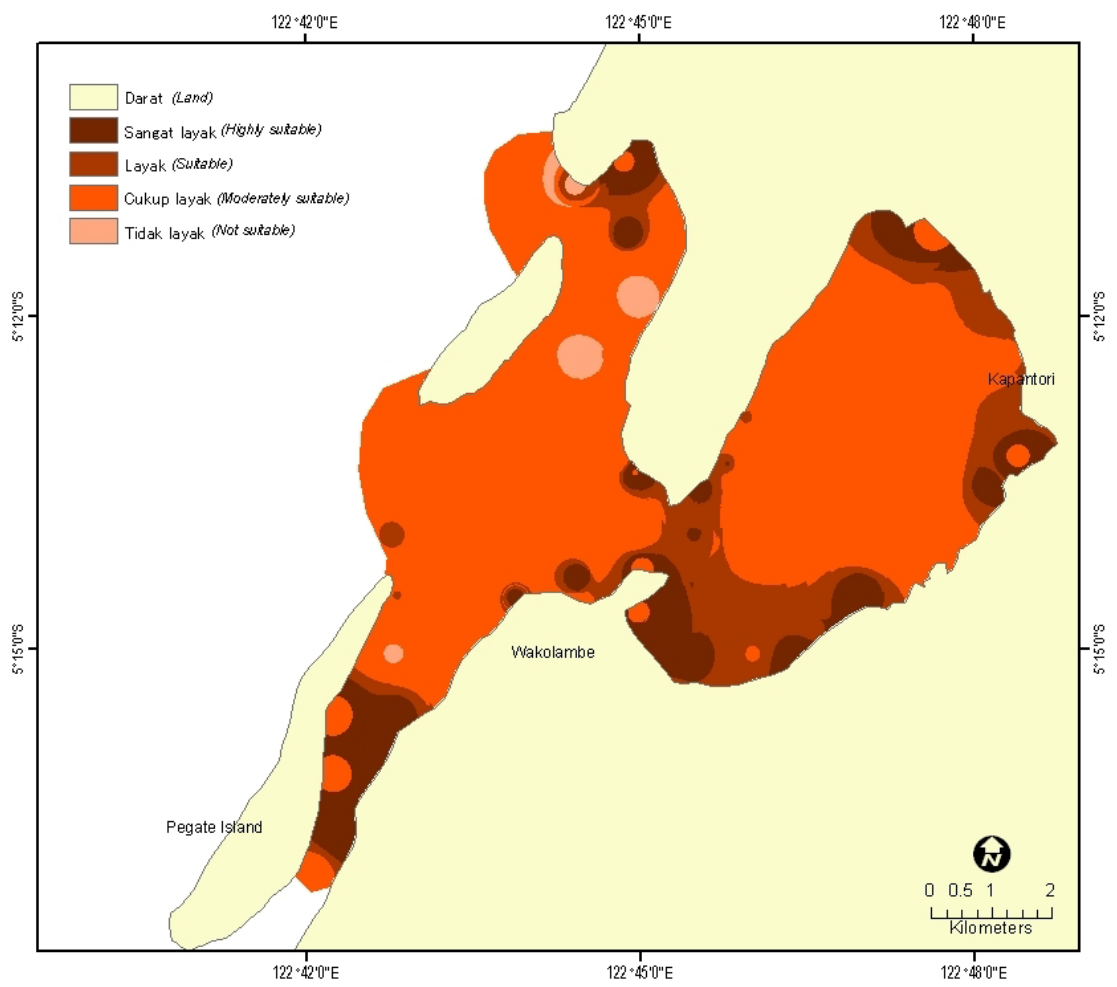

Gambar 5. Peta tingkat kelayakan lahan untuk budi daya ikan laut di perairan Kecamatan Moro

Figure 5. Suitability map for marine fish culture at adjacent water of Moro Sub District 
dipilih jenis ikan laut yang dapat bertahan hidup dengan baik, misalnya kerapu macan. Disarankan dalam implementasi pemanfaatan lokasi tersebut harus berpatokan pada kaedahkaedah lingkungan dan sesuai dengan program pengembangan pesisir dan laut secara lokal maupun nasional.

\section{UCAPAN TERIMA KASIH}

Penulis mengucapkan terima kasih kepada Dinas Perikanan dan Kelautan Kabupaten Tanjung Balai Karimun, Kepala Cabang Dinas Perikanan dan Kelautan Kecamatan Moro, dan Camat Moro yang telah membantu kelancaran pelaksanaan penelitian di lapangan.

\section{DAFTAR PUSTAKA}

Anonim. 2000. Penetapan Kawasan Lindung/ Zonasi Terumbu Karang Kecamatan Senayang Lingga. Kerjasama: Pusat Penelitian Kawasan Pantai dan Perairan, Lembaga Penelitian Universitas Riau dengan Pemerintah Kabupaten Kepulauan Riau.

Arnold, W.S., W. Whit, H.A. Norris, and M.E. Berrigan. 2000. Hard clam (Mercenaria spp.) aquaculture in Florida, U.S.A.: geographic information system applications to lease site selection, Aquacult. Eng, 23: 203- - 231.

Bappeda Riau. 2001. Reef and Village Proviling Study: Kecamatan Senayang dan Lingga Kabupaten Kepulauan Riau. Pusat Informasi and Pelatihan Terumbu Karang (CRITC)COREMAP.

Beveridge, M.C.M. 1996. Cage Aquaculture (Second Edition). Fishing News Books LTD. Farnham, Surrey, England, 352 pp.

Burrough, P.A. and R.A. McDonnel. 1998. Principle of Geographical Information Systems. Oxford University Press, 327 pp.

Buitrago, J., M. Rada, H. Hernandez, and E. Buitrago. 2005. A single- use site selection technique, using GIS, for aquaculture planning: choosing locations for mangrove oyster raft culture in Margarita Island, Venezuela. Environmental Management, 35: 544- 556.

Clark, W.A.V. and P.L. Hosking. 1986. Statistical Methods for Geographers. John Wiley \& Sons, Inc., 513 pp.

GESAMP. 2001. GESAMP (IMO/ FAO/UNESCOIOC/ MMO/ WHO/IAEA/ UN/ UNEP Joint group of experts on the scientific aspects of marine environmental Protection), Planning and management for sustainable coastal aquaculture development. Rep.Stud. GESAMP, 68: 90.

Giap, D.H., Yang Yi, and Amararatne Yakupitiyage. 2005. GIS for land evaluation for shrimp farming in Haiphong of Vietnam. Ocean \& Coastal Management, 48: 51- - 63.

Goulletquer, P. and O. Le Moine. 2003. Shellfish farming and coastal zone management (CZM) development in the Marennes- Oleron Bay and Charentais Sounds (Charente Maritime, France): A review of recent developments. Aquaculture International, 10: 507$-525$.

Johnston, K., J.M. Ver Hoef, K. Krivoruchko, and N. Lucas. 2001. Using ArcGIS geostatistical analyst, ESRI, USA, $300 \mathrm{pp}$.

Kapetsky, J.M., L. McGregor, and H. Nanne. 1987. A Geographical Information System and Satellite Remote Sensing to Plan for Aquaculture Development: A FAO - UNEP/ GRID Cooperative Study in Costa Rica. FAO Fish. Tech. Pap., (287): 51 pp.

Karthik, M., J. Suri, N. Saharan, and R.S. Biradar. 2005. Brackish water aquaculture site selection in Palghar Taluk, thane district of Maharashtra, India, using the techniques of remote sensing and geographical information system. Aquacultural Engineering, 32: $285--302$.

Malczewski, J. 1999. GIS and mutlicriteria decision analysis. John Wiley \& Sons.0 New York, $392 \mathrm{pp}$.

Nath, S.S., J.P. Bolte, L.G. Ross, and AguilarManjarrez, J. 2000. Applications of geographical information systems (GIS) for spatial decision support in aquaculture. Aquacultural Engineering, 23: 233- - 278.

Pérez, O.M., T.C. Telfer, and L.G. Ross. 2003. Use of GIS- based models for integrating and developing marine fish cages within the tourism industry in Tenerife (Canary Islands). Coastal Management, 31: 355-366.

Pérez, O.M., T.C. Telfer, and L.G. Ross. 2005. Geographical information system- based Tenerife, Canary Islands. Aquaculture Research, 36: 946- - 961.

Saaty, T.L. 1977. A Scaling Method for Priorities in Hierarchical Structures. Journal of Mathematical Psychology, 15: 234- - 281.

Pulukadan, A. 1995. Budidaya Laut Sebagai Suatu Bisnis Baru. Prosiding Temu Usaha Pemasyarakatan Teknologi Keramba Jaring Apung bagi Budidaya Laut. Jakarta, p. 35-68. 
I N. Radiarta, Saputra, A., Johan, O., dan Prihadi, T.H.

Salam, M.A., G.R. Lindsay, and C.M.M. Beveridge. 2003. A comparison of development opportunities for crab and shrimp aquaculture in south- western Bangladesh, using GIS modeling, Aquaculture, 220: 477- - 494. 